\title{
“THE PROFICIENT LAWYER": IDENTIFYING STUDENTS' PERSPECTIVES ON LEARNING GAINED FROM WORKING IN A VIRTUAL LAW CLINIC
}

\author{
Ann Thanaraj*
}

This paper seeks to identify the extent to which a Virtual Law Clinic (VLC), used as learning and training tool for undergraduate law students contribute to the development of skills and attributes of "the proficient new lawyer", looking at this from the lived experience and narration from the students involved in this training. It questions the types of skills and attributes that are perceived by students to be capable of being developed through the VLC and uses the perception of students' employability skills, personal attributes and values gained from working on the VLC platform to provide useful and significant insight into further improvements and developments to the structure and curriculum of the VLC. The value of students' perspectives in this regard is significant because the study captures their lived experiences, their thoughts, reflection and awareness of development. The findings show that students have gained benefits to their learning and have had the opportunity to gain an insight into the changing and emerging trends in legal practice and thereby raising awareness, recognition and experience of the skills needed by a proficient lawyer or professional in the workplace.

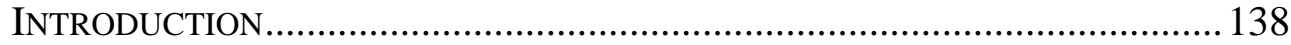

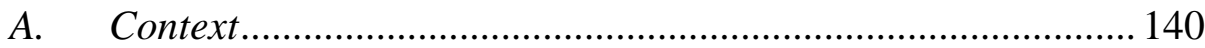

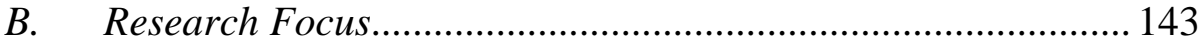

C. Grounded Theory Methodology............................................... 143

I. What TyPeS OF SKILLS AND ATtRIBUTES Is PERCEIVED By STUDENTS to

Be CAPABLE OF BEING DEVELOPED THROUGH THE VLC?........................... 147

A. Commercial Awareness ............................................................ 147

B. $\quad$ Professionalism and Principles of Values and Justice ............. 149

C. Intellectual Creativity............................................................... 153

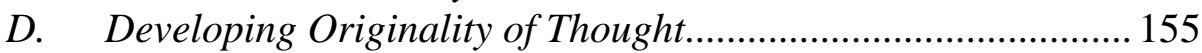

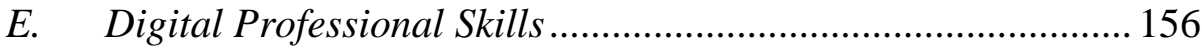

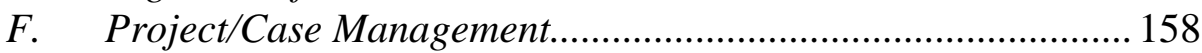

G. Engagement with Personal and Professional Development.... 159

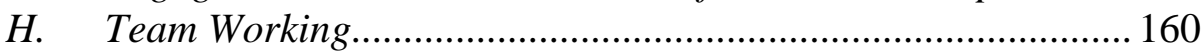

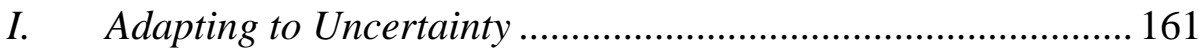

\footnotetext{
* Principal Lecturer in Law, University of Cumbria, UK. Research fields: Legal Education, Technology Enhanced Learning, Digital Education, Law and Technology, and Constructivism.
} 
II. DISCUSSION 162

III. A REFLECTION ON THE IMPROVEMENTS NEEDED TO ENHANCE THE DESIGN FOR LEARNING IN THE VLC 164

\section{INTRODUCTION}

This paper explores the perception of students' employability skills, personal attributes and values by way of an active interview method after they had the opportunity to undertake four months of experiential training on the Virtual Law Clinic (VLC). The paper offers a rich narration of the student voice in order to share the extent of learning and development of graduate skills and attributes.

The epistemological foundations of the study is founded in constructivism and social constructivism, and as such, the study follows a Straussian ${ }^{1}$ grounded theory design to guide the collecting and coding of interview data in order to identify emerging categories and generate substantive theory. Data was collected from ten participants who had completed four months of study, training and reflection on the VLC. ${ }^{2}$

An abundance of national committees has discussed the purpose of higher education. The Robbins Committee ${ }^{3}$ stated that the purposes of higher education are to a) impart employment skills and b) develop the general powers of the mind. ${ }^{4}$ One of the most prominent in the UK, The National Committee of Inquiry ${ }^{5}$ (also known as the Dearing report of 1997) introduced the agenda of aligning the delivery and purpose of higher education (HE) to that of the necessary graduate skills. ${ }^{6}$ Over a decade later, a similar tone was adopted by the Confederation of British Industry (CBI)

\footnotetext{
${ }^{1}$ B. G. Glaser \& A. L. Strauss, THe Discovery of Grounded TheORy: StRategies OR Qualitative Research (New Brunswick: Aldine Transaction 1967); and J. Corbin \& A. Strauss, Grounded Theory Method: Procedures, Canons, and Evaluative Procedures, 13(1) QuALITATIVE Sociology 3-21 (1990); and A. STRAuss, Negotiations: VARIETIES, ConteXTs, ProcesSES, AND SOCIAL ORDER (San Francisco: Jossey-Bass 1978); and A. STRAuSs, Qualitative ANALYSIS FOR SOCIAL SCIENTISTS (Cambridge, UK: Cambridge University Press 1987).

${ }^{2}$ Ann Thanaraj \& Michael Sales, Lawyering in a Digital Age: A Practice Report on the Design of a Virtual Law Clinic at Cumbria, 22(3) INTERNATIONAL JouRNAL OF CLINICAL LEGAL EdUCATION 334-361 (2015), available at: http://journals.northumbria.ac.uk/index.php/ijcle/article/view/471.

${ }^{3}$ The Report of the Committee appointed by the Prime Minister under the Chairmanship of Lord Robbins, The Robbins Report, Higher Education Report of the Committee, (HMSO1963), available at: http://www.educationengland.org.uk/documents/robbins/robbins1963.html.

${ }^{4} \mathrm{Ibid}$, at 9 .

${ }^{5}$ R. Dearing, Higher Education in the Learning Society. Report of the National Committee of Enquiry into Higher Education (London: HMSO 1997), available at: http://www.educationengland.org.uk/documents/dearing1997/dearing1997.html.

${ }^{6} \mathrm{Ibid}$, at 23.
} 
and Universities UK's report titled "Future Fit: Preparing Graduates for the World of Work" "emphasising on the use of the knowledge, skills and aptitudes gained from higher education to benefit the workplace and wider economy. ${ }^{8}$ Further, the Wilson review ${ }^{9}$ suggests that there is a gap between the needs of the UK business sector and what HE providers are offering the job market, encouraging universities to prepare students with professional and graduate level skills. ${ }^{10}$

Specific to gaps in legal practice, the Legal Education and Training Review ${ }^{11}$ in England and Wales has set out to ensure that the future system of legal education and training will be effective and efficient in preparing legal service providers to meet the needs of consumers highlighted the "skills gap ... at the initial stage of training". 12 The findings from the report shows the need for legal education and law schools to deliver curriculum which is both fitting with the needs of the regulators and one which meets the values and realities of the profession. The professional bodies in England and Wales have encouraged creativity and flexibility in law school curriculum encouraging the law schools themselves to determine how best to develop law graduates' attributes will be developed in this emergently changing legal sector.

This paper submits that the balancing of social, political and economic needs of society with the liberal academic doctrine of a subject discipline is a fine and fair balance, and one that has potential challenges to designing and assessing curriculum. The curriculum/programme philosophy needs to be determined by a university's corporate and quality, learning and teaching plan implemented in ways that meet the needs of individual subject disciplines and its benchmark standards. Getting this balance between graduates ready for employment, equipped with professional and ethical competencies and the intellectual and liberal doctrinal exploration of knowledge, understanding, analysis, reasoning, problem-solving,

\footnotetext{
${ }^{7}$ Confederation of British Industry and Universities UK, Future Fit: Preparing Graduates for the World of Work (London, CBI 2009), available at: http://www.ed.ac.uk/files/atoms/files/cbiuukfuturefit-mar2009.pdf; Also see Confederation of British Industry and the National Union of Students, Working towards Your Future-Making the Most of Your Time in Higher Education (London, CBI 2011); and UK Commission for Employment and Skills, The Employability Challenge Full Report (London, UKCES 2009), available at: https://www.nus.org.uk/Global/CBI_NUS_Employability\%20report_May\%202011.pdf.

${ }^{8} \mathrm{Ibid}$, at 17.

${ }^{9}$ T. Wilson, A Review of Business-University Collaboration (London, Department for Business, Innovation and Enterprise (2012), available at: http://dera.ioe.ac.uk/13842/1/wilson.pdf.

${ }^{10} \mathrm{Ibid}$, at 12 .

${ }^{11}$ The Legal Education and Training Review (2013), available at: http://www.letr.org.uk/thereport/commissioned by the legal professional bodies for Solicitors, Barristers and Legal Executives.

${ }^{12} \mathrm{Ibid}$, Executive Summary of the Report.
} 
substantive and procedural law is challenging in curriculum development, but one that is achievable, provided the curriculum offers an awareness and foundation for students to build on.

\section{A. Context}

The study of law involves the acquisition of legal knowledge, general intellectual skills, lawyering skills and transferable skills for the preparation of a wide range of careers. ${ }^{13}$ Within the context of legal practice, Richard Susskind, ${ }^{14}$ in his recent work "Tomorrow's Lawyers" of the legal profession requires lawyers who are not only equipped with the legal skills and knowledge necessary for the practice of law but also with a range of versatile and broader professional skills such as the ability to manage projects in time and efficiently and in an organised and inclusive manner, general management of self and teams, the ability to make decisions and show leadership and awareness and skill in the safe and proper use of technology skills. With the emerging changes to the legal profession, the need for a legal professional and lawyer to be equipped through a more technology-enabled-and-influenced legal education is in much demand. ${ }^{16}$

The Education and Training Committee of the Solicitors Regulation Authority's (SRA) "day one outcomes" 17 expected of a solicitor at the point of qualification, included the "... knowledge of ... the rules of professional conduct ... understanding of ... the values and principles ... appropriate behaviours, integrity, sensitivity to clients and others and the ability to recognise and resolve ethical dilemmas". ${ }^{18}$ Published in March 2017 in

\footnotetext{
${ }^{13}$ Subject Benchmark Statement, UK Quality Code for Higher Education Part A: Setting and Maintaining Academic Standards Law (July 2015), http://www.qaa.ac.uk/en/Publications/Documents/SBS-Law-15.pdf.

${ }^{14}$ Professor Susskind is a pioneer in the field of information technology and law and IT Adviser to the Lord Chief Justice of England and Wales.

${ }^{15}$ R. SUSSKIND, TOMORROW's LAWYERS: AN INTRODUCTION TO YOUR FutURE (Oxford University Press 2013).

${ }^{16}$ A. Thanaraj, Making the Case for a Digital Lawyering Framework in Legal Education, INTERNATIONAL REVIEW OF LAW (2017). Note: The term legal professional is used to capture Susskind's view of the potential hybrid professional equipped as a lawyer and proficiencies in IT, project management, accountancy and so on.

${ }^{17}$ A new framework for work based learning: Consultation — Annex 1-Day one outcome-

"Knowledge of ... the rules of professional conduct (including the accounts rules) ... understanding of ... the values and principles on which professional rules are constructed ..." available at: http://www.sra.org.uk/solicitors/qlts/day-one-outcomes-table.page.

${ }^{18} \mathrm{Ibid}$, annex outcome C and D.
} 
Canada the "Foundations for Practice"19 empirical study undertaken by the Institute for the Advancement of the American Legal System (IAALS) identifies the key foundations that new lawyers require when entering the legal profession. The report defines the core foundations of a new lawyer as integrity, a strong work ethic, resilience and common sense. These foundations would form the basis of an ethical and reflective practitioner. The paper also considers whether the necessary characteristics required of a proficient lawyer can be learned and how to measure these traits. ${ }^{20}$

It is suggested in this paper that curriculum in the legal education curriculum should be capable of developing the intellectual skills, knowledge and understanding to empower students through satisfaction and self-esteem as their personal potential is realised and consequently, the development of the general powers of the mind ${ }^{21}$ through professional and transferable employability skills valued in the workplace. As such, philosophically, economically and socially, it is possible to agree that this fine and fair balance of competing purpose of HE should be one that is capable of equipping a graduate with personal and professional attributes, intellectual curiosity, skills and understanding of both office based and online working practices, with a thorough theoretical grounding on digital lawyering skills and its ethical and practical application through academic and extracurricular activities in a curriculum - this is what is deemed as "the proficient lawyer" for the purpose of this study.

As such, a Virtual Law Clinic ${ }^{22}$ was designed as an online professional working platform which facilitated learning and training collaboration between students, tutors and solicitors, designed to enhance the legal education of students through direct experience of legal practice. To facilitate meaningful and relevant learning in an innovative take on clinical initiative created using technology to enable the learning, required involvement and active engagement from law firms. From the literature on technological innovations, ${ }^{23}$ it is clear that technology is continuing to

\footnotetext{
${ }^{19}$ Foundations for Practice: The Whole Lawyer and the Character Quotient by the Institute for the Advancement of the American Legal System (IAALS), available at: http://iaals.du.edu/educatingtomorrows-lawyers/publications/foundations-practice-whole-lawyer-and-character-quotient.

${ }^{20} \mathrm{Ibid}$.

${ }^{21}$ Subject Benchmark Statement, UK Quality Code for Higher Education Part A: Setting and Maintaining Academic Standards Law (July 2015), http://www.qaa.ac.uk/en/Publications/Documents/SBS-Law-15.pdf.

${ }^{22}$ Ann Thanaraj \& Michael Sales, Lawyering in a Digital Age: A Practice Report on the Design of A Virtual Law Clinic at Cumbria, 22(3) INTERNATIONAL JOURNAL OF CLINICAL LEGAL EDUCATION 334-361 (2015), available at: http://journals.northumbria.ac.uk/index.php/ijcle/article/view/471.

${ }^{23}$ A. Thanaraj, Making the Case for a Digital Lawyering Framework in Legal Education, INTERNATIONAL REVIEW OF LAW (2017).
} 
change the way we work and the way law firms work and consequently impacting the way law schools prepare students for legal and professional practice.

The purpose of the VLC is to provide students with the necessary skills and competencies to confidently enter legal practice and become productive more quickly, and to use technology to enhance the teaching of lawyering skills required to meet the emerging trends in the delivery of legal services. It also aimed to make a meaningful contribution to the development of our own law graduates, ensuring that they are ready to enter the professional workplace, and to offer suggestions to the wider network of law schools tackling the same challenges as we are.

From a broader perspective, with the evolving business needs due to technological developments, skill set and flexible ways of working, universities should create opportunities for students to engage with continual learning, becoming aware of their own skill sets and their transferability and adaptability and to gain the necessary working knowledge of professional environments. Skills such as problem solving, teamwork and communication are in most demand in the workplace according to the "Economist" 24 in 2015. Being able to apply those skills in an online professional environment requires guidance, practice and a different set of knowledge for application.

A recent paper on "Making a case for a digital lawyering framework" 25 discusses the extent of technological initiatives undertaken in legal practice and in the courts across the UK, US and many other jurisdictions and opines a possible digital lawyering curriculum to try and bridge the gap.

It is intended that the experience and learning gained from the VLC (conceptualised by way of constructive reflection) assists in building a holistic skillset and competencies which are required to create "the proficient new lawyer" when entering a modern legal practice environment as well as adapting to new ways of working within the profession. The intended competencies include:

- Value the role of legal ethics, personal responsibility and accountability online.

- Apply and maintain personal responsibility and accountability in both individual and group contexts online;

\footnotetext{
${ }^{24}$ The Economist, Driving the Skills Agenda: Preparing Students for the Future, An Economist Intelligence Unit Report, sponsored by Google (2015), available at: https://www.eiuperspectives.economist.com/sites/default/files/Drivingtheskillsagenda.pdf. ${ }^{25}$ A. Thanaraj, Making the Case for a Digital Lawyering Framework in Legal Education, INTERNATIONAL REVIEW OF LAW (2017).
} 
- Develop effective collaboration skills online;

- Understanding the nuances of undertaking professional work online;

- Applying key workplace related skills such as team working, managing projects, general etiquette, and problem solving onto an online working environment;

- Develop, understand and experience online dispute resolution, using the practice of digital lawyering skills;

- Experience online practice management;

- Appreciate the role of technology, privacy and security in legal practice and in the wider professional workplace.

\section{B. Research Focus}

This paper seeks to identify the extent to which the VLC as a learning and teaching methodology contributes to the development of graduate skills and attributes of "the proficient lawyer", using the lived experience and voice of the students who have undertaken learning on the VLC platform. In order to identify students' perception of the different types of graduate skills and attributes capable of being developed via training on the VLC, this grounded theory study aims to explore the following research questions:

1. What types of skills and attributes is perceived by students to be capable of being developed through the VLC?

2. Using the findings to undertake a reflection on the improvements needed to enhance the design for learning in the VLC.

The perception of students' employability skills, personal attributes and values gained from working on the VLC platform will provide useful and significant insight into further improvements and developments to the structure and curriculum of the VLC. As such, these findings will offer a distinctive contribution to knowledge in the areas of employability, technology in clinical education, reflective learning and experiential learning, to name a few.

\section{Grounded Theory Methodology}

My epistemology stance is grounded in the constructivism. This matches the methodology framework in that grounded theory provides an effective approach to build new theories about a topic of research and understand how empirical observations or data can contribute to this 
development. ${ }^{26}$ It also provides a structured and rigorous method of analysis. In keeping with the acceptable review of literature using the Straussian grounded theory methodology, the judiciously conducted review has helped me with framing the research questions and to identify appropriate data collection methodology. Apart from using the literature to frame the research focus and to provide a context to balance the need to focus on employability with the liberal academic doctrine of a subject discipline, the conduct of the study and the analysis of the findings will be the only influences in the generation of theory. ${ }^{27}$ Because the VLC is still relatively a new training tool used in the curriculum, this methodology provides new and useful insight into the potential and limitations of the VLC from students' perspectives.

\section{Method}

Ten students were selected through purposeful sampling but their participation was entirely voluntary from a pool of nineteen students. They had personal experiences of studying this module online; together with their enthusiasm to participate and their desire to reflect and share their experience. Consent was obtained, the purpose of the research was explained to each participant, and anonymity was assured. Data was gathered using an active interview approach ${ }^{28}$ where both the interviewer and participant are active in dialogue during the interview as "constructors of knowledge in collaboration with interviewers". ${ }^{29}$ In this way, it was an opportunity to suggest or question more deeply narrative positions or viewpoints for the participant to engage in during the interview. This helps to guide the participants' thoughts to make connections between the topic and experiences. Each participant was interviewed once lasting around twenty minutes.

Prior to the interview, the following discussion points were sent in advance to the participants:

- Advantages of working in the VLC;

\footnotetext{
${ }^{26}$ P. Martin \& B. Turner, Grounded Theory and Organizational Research, 22(2) THE JOURNAL OF APPLIED BEHAVIOURAL SCIENCE 141-157 (1986), available at: http://journals.sagepub.com/doi/abs/10.1177/002188638602200207.

${ }^{27}$ J. Corbin \& A. Strauss, Basics of Qualitative Research: TeChNiQues AND Procedures For Developing Grounded Theory (3rd edition, Thousand Oaks, Sage 2008); and A. Strauss \& J. Cobin, Basics of Qualitative Research: TeChNiQues and PROCEDURES FOR DEVEloping Grounded THEORY (2nd edition, Thousand Oaks, Sage 1998).

${ }^{28}$ Patton M., Qualitative Research and Evaluation Methods (3rd Sage Publications, Thousand Oaks, CA 2002).

${ }^{29}$ J. A. Holstein \& J. Gubrium, The ACtive InTERVIEW 4 (Thousand Oaks: Sage 1995).
} 
- Challenges faced in working in the VLC;

- Discuss the types of skills you gained from working in the VLC;

- Discuss the types of characteristics and attributes you developed from working in the VLC;

- What skills or characteristics did you hope to develop through the VLC?

- What skills or characterises did you feel you were not able to develop from using the VLC?

- The entire module is based on team working, what are the benefit from interacting with others online in terms of understanding the subject matter or challenging personal own views and opinions;

- Please share any further thoughts or comments you may have about the construction of the VLC, how it is being used or suggestions on how it can be improved.

\section{Analysis Process}

The analysis began with writing notes after each interview to capture initial ideas and make comparisons between participants' accounts. The notes were reflective of what I learnt from the dialogue and helpful in guiding the next interview, allowing to make comparisons between each interview, see any changes in perspectives, find patterns in students' perceptions and to question my assumptions in relation to the VLC or employability skills and attributes in relation to the interview data. The interview scripts were read and analysed right after each interview to allow me to capture the non-verbal nuances of each interviewee.

Next is the analysis undertaken via a three-step coding process. According to Charmaz (2006) "coding is the pivotal link between collecting data and developing an emergent theory to explain these data...${ }^{30}$ In this study the steps used for coding were guided by the Strauss and Corbin framework. Coding occurred in three stages:

(1) Open coding

The coding commenced as soon as the first interview transcript was complete and this process was repeated after each interview. Using the data from the participants, the coding involved identification, labelling, drawing categories and adding descriptions to the research phenomenon. Codes are assigned to key words and sentences to expose the thoughts, ideas and

\footnotetext{
${ }^{30}$ Charmaz K., Constructing Grounded Theory: A Practical Guide through Qualitative ANALYSIS 46 (London: Sage 2006).
} 
meanings contained in the text. ${ }^{31}$ This developed a deeper understanding of the data and increase familiarity with the participants' words, thereby maximizing theoretical sensitivity towards the data. This process was performed simultaneously alongside examining codes from previous transcripts whilst reflecting on possible relations, similarities or dissimilarities between the codes. ${ }^{32}$

\section{(2) Axial coding}

This stage involves analysing the selected codes in relation to the context of the situation throughout the entire dataset and the study. ${ }^{33}$ The process begins with making decisions about data codes which are deemed to contribute most to the analysis through several reiterations between the data collection and data analysis process, looking for patterns in similarities and differences.

(3) Selective coding

The final stage of the analysis is to represent the central phenomenon of the study around which all the other categories are integrated. The final categories are refined and validated to show how they relate to the data by way of narratives of the participant's experience, to determine how well they stand up to such scrutiny. ${ }^{34}$

\section{Assumptions and Limitations of this Study}

- From a constructivist viewpoint, where knowledge and meaning is created in different ways with different interpretations because of our varying epistemology and ontology, it is possible that other researchers might have developed different categories of codes from the data, since grounded theory analysis is an interpretative process rather than an objective report.

- Grounded theory is built on the premise that theory emerges from the data collected and analysed. There is no allowance or acceptance of the influence, perspectives and lived experience of the researcher in the analysis and coding process. ${ }^{35}$ It is argued that it is not possible to start a research study without pre-existing ideas and assumptions but it is essential to

\footnotetext{
${ }^{31}$ A. Strauss \& J. Corbin, Basics of Qualitative Research, Grounded Theory Procedures and TECHNIQUes (New York: Sage Publications 1990).

${ }^{32}$ Ibid

${ }^{33}$ Ibid.

${ }^{34}$ A. Strauss \& J. Corbin, Basics of Qualitative Research, Grounded Theory Procedures and TECHNIQUES (New York: Sage Publications 1990).

${ }^{35}$ E. G. Glaser, Advances in the Methodology of Grounded Theory: Theoretical Sensitivity (Mill Valley, California: Sociology Press 1978); and Charmaz K., CONSTRUCTING GROUndED Theory: A Practical Guide through Qualitative Analysis (London Sage Publications 2006).
} 
maintain an open and non-biased approach to the emerging data.

- The generalizability of the findings is a limitation to this research. The study considers the experience and perceptions of only ten undergraduate students who have worked on the VLC programme. The findings may not be extendable to the wider student population who have undertaken the VLC programme at this university or to those who have undertaken a similar VLC programme at another university as results could vary with a greater number of participants. It is submitted nevertheless that the findings of the study will be helpful in further developments and improvements that need to be made to the VLC to ensure that it can meet the learning objectives as effectively as possible. Further, the findings may help spark some interest and discussion amongst students and academics as a learning methodology which could be utilized in their own curriculum.

- The responses from the participants depended on their conscious awareness of employability, skills and attributes and related challenges and their ability to reflect, identify and effectively communicate all the relevant information. It is assumed that the participants provided honest and accurate answers. Greenstein ${ }^{36}$ had warned that there are tendencies to alter behaviour and beliefs when participating in a research study or provide answers that are biased in the direction of socially acceptable attitudes. Biases and prejudices can also feature in responses. However, the data collected is assumed as a true reflection of the participants' view.

\section{What Types of Skills AND AtTRIButes Is Perceived By Students to Be CAPABle of BeING DEVELOPED THROUGH THE VLC?}

\section{A. Commercial Awareness}

The findings demonstrate some awareness of business and commercial acumen developed from undertaking work on the VLC. In legal practice, it is not only important for lawyers to meet client expectations, they also need to understand and adapt to the socio-political and economic contexts in which those clients function, and in particular the business needs of the clients.

\section{Aptitude towards Business and Entrepreneurial Skill}

P1: As a team leader of my firm I was responsible for identifying new challenges and opportunities for us to work on, whether it was in

\footnotetext{
${ }^{36}$ T. N. GreEnstein, Methods of FAmily Research (2nd ed. Thousand Oaks, CA: Sage 2006).
} 
the form of a collaborative research project for wider community dissemination or a new legal matter that required research and advice. I learnt quickly that setting goals, action plans to achieve these goals and organisation skills were crucial in running the team. I also learnt that opportunities come with risks so I had to ensure that risks were considered and carefully addressed too.

P10: We were required to create an identity for the team. We set out to identify a brand, name, logo, tagline, typeface for all our documentations. This gave us a professional identity and motivation to carry out work according to the standard our brand claimed to provide. Clients frequently ask us about our firm's logo.

P7: To list a few characteristics ... thinking outside the standard text, problem solving, being creative and practical ... good social skills.

Business acumen and commercial awareness are essential skills needed in any professional workplace. Students' awareness of its importance will facilitate focus on developing and improving these skills in the need to offer clients the best possible experience, both in their care and in the quality of work provided.

P3: It is important that the client's expectations are addressed and their issues resolved. Lawyering involves a mixture of legal knowledge and practical commonsensical knowledge. I have had to work creatively and innovatively to solve problems and identity solutions. Together with my team members, we found that stepping back and reflecting on the choices and decisions we were making were helpful in ensuring we were doing things logically, professionally and with best interest at heart.

P4: We are all collaboratively responsible for managing a case or project from start to finish, working through tight and competing deadlines as well. It was really interesting to see how to run a small firm with three other team members, managing team dynamics, ... were beyond anything a textbook can teach us.

P8: Especially online ... communication is different, somewhat easier ... Because we are working toward a common goal of achieving the best for our client, relationships within the team is built on maturity, professionalism and trust.

\section{Building and Maintaining Strong Relationships}

P1: ... invest in good relationship skills. I have learnt both from my experience with clients on the VLC and with work experience in 
law firms that this means an awareness and understanding of emotional intelligence, the ability to empathise, persuade, collaborate and influence. It is just as important that there is mutual trust between two people for any form of relationship to develop.

P4: Persuasive skills are important to build a successful business and for team working, taking the team with your vision ... using wellresearched information and opinion...

P5: Business approaches ... the best approach would be to take a holistic approach, evaluate issues and make decisions in situations and assess the risks.

P8: Being inclusive, seeking opinions, promoting discussion versus being able to take the initiative, show self-discipline and take charge of a project is difficult - but the balance is a much needed necessity in the workplace.

\section{B. Professionalism and Principles of Values and Justice}

The LETR ${ }^{37}$ highlighted the teaching of professionalism and professional ethics as "critical defining feature of professional service" 38 highlighting the need for legal educators to facilitate their students in developing a good overall professional character.

Prior to this study, in 2007, the Carnegie Foundation for the Advancement of Teaching, in a report titled "Educating Lawyers: Preparation for the Profession of Law" noted that "the formation of a professional identity with a moral core of service and responsibility" 39 needs to be embedded and taught as part of educating future lawyers. Similarly, also in 2007, the Clinical Legal Education Association's study titled "Best Practices for Legal Education" emphasised the importance of teaching practice and professionalism at the centre of legal education. ${ }^{40}$ However, until recently the method and content of the teaching raised concerns across the legal sector from legal academics to practitioners. ${ }^{41}$

As such, this paper argues that legal education needs a more integrated, holistic approach towards educating future lawyers, whereby knowledge,

\footnotetext{
${ }^{37}$ The Legal Education And Training Review (2013), available at: http://www.letr.org.uk/thereport/.

${ }^{38}$ Legal EduCATION AND TRAining Review 34 (2013), available at: http://letr.org.uk/.

${ }^{39}$ Sullivan et al., Educating Lawyers: Preparation for the Profession of Law, THE CARNEGIE FOUNDATION FOR THE ADVANCEMENT OF TEACHING 187-188 (2007), available at: http://archive.carnegiefoundation.org/pdfs/elibrary/elibrary_pdf_632.pdf.

${ }^{40}$ R. Stuckey, Best Practices for Legal Education (2007), available at: http://www.cleaweb.org/Resources/Documents/best_practices-full.pdf.

${ }^{41}$ Legal EduCATION AND Training Review 35 (2013), available at: http://letr.org.uk/.
} 
application, skills and professionalism are taught coherently across the curriculum, with at least one module dedicated to addressing professional values, ethics and raising awareness of experiential lawyering, with a view to pervasively embed a curriculum on digital lawyering and professional skills.

P3: ... where we had to think more practically about the application of the law ... in real life, rather than in for an academic assessment ... Having to apply the law in a way that has an impact on someone's life made me sit up and think very carefully about what I know, what I need to know, how I apply what I know to [this] situation ... Overtime I began to develop an identity of the type of "lawyer" I will be, a sense of values that I base my decisions on...

P5: ... aware of the importance of developing [my] own identity as a professional because of the emphasis in the VLC training...

P6: ... I think it is about competency-meeting the standard expected of any lawyer-I would like to do better than just minimum, but yeah, professionalism is about at least getting to that standard and being responsible towards the client ... In the VLC, ethics and skills become part and parcel of the daily work. Because it is online, it was a different set of skills to learn ... adapted from what I was used to...

P7: ... Helped me appreciate more about working online. I did take it for granted ... well it's just a message online-but when your undertaking professional client work online, then acting responsibly and doing the right thing is really important, in fact more important because to an extent we are compensating for the lack of personal contact ... That's why I took it much more seriously...

P8: In my time as a law student I have not had the responsibility or opportunity to make so many decisions until I started on working the VLC. Simple decisions from when and how to hold team meetings to time keeping to more complex ones such as which practical advice is better suited to the client or what researching strategy to use or what style of negotiation is best, especially when it is online, there is an additional challenge.

P10: ... but decision making was the highlight of working on the VLC. We developed a team ethos to make decisions - research, reflect and provide a rationale for the decision. In this way, we are making an informed judgement.

Acquiring the skills of competent lawyering requires grounding in both theoretical and applied knowledge that can only be gained in the actual 
experience of practical application of the law. Most crucially is the role that embedded reflection contributes to students' learning, awareness and consequentially improvements to their knowledge, skills and aptitudes. Once a systematic reflection is undertaken, it is important that the findings of the reflection are discussed with a supervisor for feedback and to set out action plans to address areas of improvement. This constructive process allows for competency to be developed and learned. ${ }^{42}$

P1: Being professional means undertaking work on behalf the team or for the team or client to the highest standard possible ... Knowledge about the standard is important ... Need to learn and understand the role of a modern lawyer ... Many of the administrative and secretarial systems are moving online, but so is the negotiation and many of the client interviews, so we need to learn tech awareness. In my view it means what tech to use, how to use the tech, how to use it safely, reassuring about confidentially and privacy ... During my work experience, I even managed to advice a firm's managing director about their use of technology.

P2: When I began my first legal matter online I became immersed in the online lawyering skills, refining it and reading widely to make sure that I was becoming competent in this challenging and new environment.

P3: I developed much of my awareness of working professionally thought this training. I have learnt to set goals, set a plan on how to achieve these and successfully meet each objective. Of course, reflection is the key to becoming aware of my actions and learning from what I did well and what I need to work on.

P8: ... a component of the reality of working in the online firm was the practice of professional skills, business related skills and behaviours ... helped me grow in confidence and persevere to achieve the best for the firm and for the client in challenging situations.

P10: Professional skills or real world skills require such detailed knowledge and understanding of client care, business practices and it is important to innovate and offer creative solutions to challenging and complex problems. ... In combination all of these skills and awareness contribute to understanding what it means to be professional.

They need to have an understanding of the administrative and

\footnotetext{
${ }^{42}$ A. Thanaraj, Constructive Reflection: Getting the Best Out of Reflective Learning, InTERNATIONAL JOURNAL FOR INNOVATION, EDUCATION AND RESEARCH (2017), available at: http://www.ijier.net/index.php/ijier/article/view/500/540.
} 
operational environment under which business is conducted on a daily basis such as understanding what makes a business successful and an appreciation of the factors that influence success for their advice to have any reliability and relevancy.In addition to this, learners gain awareness for ethics in the context of digital lawyering, which includes the use of online platforms such as the VLC and practice management tools, as well as an appreciation for data security and storage.

P2: ... This choice of how we conduct ourselves gave us the freedom to explore what works for us, and trial out various strategies and styles of negotiating without being prohibited as long as we met the best interest of the client ... and followed the professional codes and practices ... the mentoring and reflection after the negotiation helped clarify what worked well and this helped me learn how to negotiate...

P4: I am dedicated and committed to doing the best for my client and her cause ... I think my client trusts me to do the best for her. I keep her informed of progress, and she can see it from the practice management software, I respond to her questions promptly ... pay attention to my communication ensuring that there are accurate details included ... take responsibility for the work I produce and even when things go wrong, I try my hardest to make amends.

P5: The VLC gave me an insight into what legal practice will be like in a few years' time. I have used my experience and considered best practice literature on how to establish a professional lawyer-client relationship online, improve online written and verbal communication including developing an awareness for verbal and non-verbal cues ... Found this to be important when the client is on a screen.

P6: This experience has challenged me to question the challenges and risks of working online and to be professional online ... Online resonates with games, but in fact this is the reality for some law firms I have done work experience in.

P7: Working on an online professional platform has helped me think about cybercrime, computer fraud, how to store data, identity fraud. An awareness of these challenges have prompted me to undertake further readings on these areas so that I can handle work for my clients in a safe and professional manner. The training within the VLC also covers a number of "safe" practices to avoid cybercrime attacks. I have also created a guide as part of my final year project for clients on how avoid being attacked by cybercrimes such as using double authentication process, when and when not to provide 
information when making an online purchase...

P10: I have gained an interest in digital governance ... huge benefit for law firms and hopefully to become a solicitor specialising in IT law, thanks to the VLC module.

\section{Intellectual Creativity}

Curriculum design should strive to positively enhance and enrich the lives of learners, drawing out their creativity and encouraging new ways of thinking. When students are encouraged to be creative, think independently and identify authentic solutions to problems, this is a powerful way of developing a holistic intellectual and professional experience, allowing for deeper and richer learningand building confidence in students.

P1: The hands-on experience of VLC gives us space to reflect and think, helping us to understand what it is that we are learning ... and to improve.

P5: As I would be required to deal with situations in a workplace, working on the VLC required that I assess situations with clients, team members and supervisors, decide on any action that needs to be taken, areas for improvement ... undertake reflection on the experience to ensure that I have had time to think and learn from the work undertaken. Having the experience to undertake all this online with a client has been challenging.

By carrying out creative tasks and subsequently reflecting on and evaluating the actions taken, learners will be able to assess their performance and learn from their experiences. The reflective process encourages students to autonomously learn from their own actions and experience.

P2: The authenticity of the VLC gave me a chance to experience and practice actual lawyering ... capacity to creatively find solutions to problems. It has also created opportunities to learn about how technology is shaping legal practice, handling online project management and undertaking online negotiation. There were challenges, not with the technology, but with the unanticipated requirements of additional skills, preparation and planning...

P5: The tasks are arranged to allow creative decisions as a team and to work freely in ways that allow us to develop our professional identity. The VLC offers demanding and exciting work which encourages experimentation, evaluation and personal development. There is opportunity for continuing academic debate and dialogue with 
supervising solicitors and tutors about competencies of skills, best practice, changes in law firms. Most importantly the embedded constructive reflection structure has made me realise my personal strengths and limitations.

The findings reveal that creativity, authenticity and reflection are a powerful mechanism behind learning. It is clear that experience may help to inform and influence students' learning but actualization of that learning takes place from reflecting on an experience. The results demonstrate a connection between the reflective evaluation process and student performance. This conceptualization of reflection and learning can lead to intellectual creativity and demonstrable intellectual skills of a high order.

In order for students to develop, explore and refine their creative and professional thinking skills, the space created and the activities embedded into a learning task needs to promote the requisite opportunity for critical thinking and creative problem solving skills.

The learning experience in the VLC adopts some of Bloom's digital taxonomy ${ }^{43}$ of cognitive development to create a creative and challenging space. From the findings, students feel empowered to make objective judgements, overcome challenges and make sense of their learning.

P1: The transactions within the VLC required us to think deeply and purposefully ... We then applied our evaluations to the client's situation. We are constantly "thinking outside the box"-practically, looking at different perspectives, being creative to solve problems...

P4: The way I approach a problem-my thinking and evaluation skills-has evolved and matured. I am more reflective in my approach, focusing on the problem that needs to be solved, the people involved, wider impact on all parties involved including the opponents. I think carefully about the reasons for my decision. I have learnt to consult the competency statements...

P7: The VLC offers a space to play with ideas, possibilities. We are given the autonomy to deal with challenging situations ... opportunity to be creative and think creatively.

The VLC is designed in such a way that enables students to trial new concepts and ideas. A learner can select the most appropriate way to progress with a transaction and exercise their problem solving and reasoning skills. The embedded constructive reflection is central to the VLC and this

\footnotetext{
${ }^{43}$ A. Churches, Blooms' Digital Taxonomy (2007), available at: http://edorigami. wikispaces.com/Bloom's+Digital+Taxonomy.
} 
encourages learners to evaluate the way in which they learn and identify their strengths and weaknesses with a degree of autonomy.

\section{Developing Originality of Thought}

Learning is not a passive process and requires individuals to build their own understanding and knowledge based upon experiences and reflection.

P3: Within the VLC construct we are given the opportunity to build our own understanding and appreciation for various lawyering processes and competencies ... some space to take risks, getting it wrong was ok, it is part of the learning, I know what to do and not to do ... Learning from mistakes, having the chance to try techniques out ... reflecting and bridging what we knew and what we now know helped with generating new ideas.

P4: There was opportunity throughout the process to be creative and imaginative in our techniques and problem solving skills ... Personally, this helped me develop deeper understanding of working with people ... professional skills, lawyering skills ... and to reflect on how to improve what I am currently doing.

P5: The space within the VLC process which required us to undertake the constructive reflection stage was methodological and structured. It allowed me to explore the how, what and why questions in relation to my reactions, decisions, ideas more deeply .... Developed my own skills technique ... and independent thought .... More confident in a collaborative environment.

P6: The VLC helped me become independent in my thinking, learning, in taking control over my career progression and setting myself goals to achieve my ambitions. I have found that becoming independent and taking responsibility for my learning has motivated me to contribute within the team, in coming up with more confident ideas with sound rationale. This motivation was largely due to the independent nature of the work involved in the VLC ... although we had to always keep in mind the necessary professional rules and expectations of the tutor and clients.

P10: I would say the VLC, its process, the learning derived from it, the way we work ... allows us to be creative and imaginative ... has helped us (team members) to develop skills and knowledge ... probably because of the technology aspect which gives us the flexibility to work as much as we want and from where we want without the constrains of location and timing, probably because of the 
need to know how to work online for employability purposes ... make connections through creative and critical thinking is a skill integrated into the learning within the VLC.

The VLC platform empowers students to carry out their own research and analysis on genuine client cases. Students are often presented with incomplete information which requires them to utilise their problem solving skills in order to find a satisfactory solution. To create graduates who are able to handle the complexities of the professional world of work, tutors need to provide students with the opportunities to gain real-world experience and be reflective about their performance and personal development requirements. All of these facilitate the opportunity for learners to develop their intellectual capacity of the highest order whilst creating original and creative thoughts.

\section{E. Digital Professional Skills}

Technology has offered a vast array of communication and collaboration opportunities, and these have been used to enhance learning opportunities in curriculum. It must be said however that technology should only be used because there is rich pedagogy underpinning its use and because there is a clear link to a type of learning which technology afford. As such, technology should not be used for the sake of using it.

Susskind $^{44}$ who is Chair of Civil Justice Council's Online Dispute Resolution Advisory Group and IT Adviser to the Lord Chief appeals to academics to consider how legal education and training takes into consideration the role that technology has begun to play in the profession, especially in light of the emerging changes to the delivery of legal services. Significant changes to legal services are beginning to emerge and technology is playing a central part in these changes. ${ }^{45}$ For example, the Legal Services Consumer Panel's report ${ }^{46}$ points out that the digital technologies have impacted upon the provision of legal services and the structure of law firms, identification of legal issues and how businesses and individuals handle disputes.

\footnotetext{
${ }^{44}$ R. SUSSKIND, TOMORROW's LAWYERS: AN INTRODUCTION TO YOUR FUTURE (Oxford University Press 2013).

${ }^{45}$ A. Thanaraj, Making the Case for a Digital Lawyering Framework in Legal Education, INTERNATIONAL REVIEW OF LAW (2017).

${ }^{46}$ Legal Services Consumer Panel in November 2014 on "2020 Legal Services: How regulators should prepare for the future", accessible at:

http://www.legalservicesconsumerpanel.org.uk/publications/research_and_reports/documents/2020co nsumerchallenge.pdf.
} 
P2: The VLC is an innovative example of a course which is extremely current ... future skills of the profession. It contains opportunities to learn about alternative forms of technology-driven legal service delivery, and the ethical rules of online practice...

P3: It offers practical ways of using technology to undertake client work, increase efficiency of practice whilst gaining experience in online dispute resolution, e-practice and project management are valuable employability skills ... Law firms have been keen to find out about what I am studying in this module.

P5: ... technical, theoretical and practical knowledge on matters such as handling client confidentiality and the communication, storage and security of client data are absolute core requirements of a digital lawyering curriculum.

Further, an impetus to teach digital lawyering skills to students is from the American Bar Association (ABA) E-lawyering Task Force, which state that "to be successful in the coming era, lawyers will need to know how to practice over the Web, manage client relationships in cyberspace, and ethically offer 'unbundled' services". 47

P8: In leading a team within the VLC, there was much resemblance to running one's own business. It would have been helpful to have some course information on models of entrepreneurship, innovative models of online law practice and helpful enterprising and business skills.

P9: ... I have experienced how technology is being used to reach clients who otherwise would not be able to access legal advice ... Further, there are new and effective ways of organizing and delivering legal work ... becoming more responsive to the needs of clients ... affordable and accessible, using an online practice that is secure and efficient is essential.

P10: ... It is most important that client-centred approach and good customer service is paramount to a successful practice ... quick and timely turnaround to client's response.

As such, an opinion on a potential digital lawyering framework for adaptation by law schools has been discussed in a previous paper ${ }^{48}$ looking

\footnotetext{
${ }^{47}$ ABA E-lawyering Task Force, Law Practice Division, available at: $\mathrm{http} / / / \mathrm{apps}$.americanbar.org/dch/committee.cfm?com=EP024500.

${ }^{48}$ A. Thanaraj, Making the Case for a Digital Lawyering Framework in Legal Education, INTERNATIONAL REVIEW OF LAW (2017).
} 
at the integration of experiential ${ }^{49}$ learning processes to develop "a digitally proficient new lawyer" through the design and development of a bespoke virtual law clinic application and an integrated theoretical curriculum alongside structured reflection. ${ }^{50}$

\section{F. $\quad$ Project/Case Management}

With regulation changes through the Legal Services Act 2007, the need for efficiency and transparency, globalisation of legal services and technological advanced in legal practice, the skill for project management is in high demand. Individuals need to be able to break down projects and manage cases in structured sets of tasks in order to work in an efficient and effective manner within an organisation.

P1: The VLC required team leaders to also take on the role of project managers ... thinking about schedule, setting deadlines and objectives that need to be achieved and identifying strengths of team members.

P2: I had not realised the need for alternative plans. We were not fluid to change as a team ... So when there was a change in the requirements from the client we hadn't taken an integrated approach to make changes to deadlines, keep to tasks that could be completed within the deadline and review any risks. However, this is when I learnt that the value of project management skills-being efficient, transparent and goal oriented.

P4: Managing a case is like managing a project ... I learnt quickly that the project planis in fact aliving document which can be expected to change as the project progresses...

P5: ... a key factor is the quality of the work being produced, ensuring that the research, advice notes, letter or presentation meetsthe client specifications ... preventing errors, meets the standards of the profession.

P10: The project management software gave us some experience of using an electronic system to learn about the knowledge, skills and processes to be aware of when planning a case. It was an eye opener

\footnotetext{
${ }^{49}$ D. A. Kolb, Experiential Learning: Experience as the Source of Learning and Development, 1 Englewood ClifFS (NJ: Prentice-Hall 1984); and D. A. Kolb, I. M. Rubin \& J. M. MCINTYRE, ORGANIZATIONAL PSYChOlOGY: READINGS ON HUMAN BEHAVIOR IN ORGANIZATIONS (Prentice Hall 1984).

${ }^{50}$ A. Thanaraj, Making the Case for a Digital Lawyering Framework in Legal Education, INTERNATIONAL REVIEW OF LAW (2017).
} 
understanding the business-related aspect of law practice - assigning time, people, and cost and meeting clients' expectations...

\section{G. Engagement with Personal and Professional Development}

Embedded into the VLC curriculum is a constructive reflective model that offers students a layered and developmental approach to embed learning and the application of learning within the seemingly constantly changing professional environment. ${ }^{51}$ The model embraces the influences of personal epistemology of assumptions and consciousness and recognises how our identity, values, opinion and experiences impacts on the way we react or behave in particular situations.

P1: The ability to reflect my practical lawyering skills helped me measure and realise my level of competency. The structured and guided approach helped me learn about the necessary competency, assess my standards against that, identify specific areas that needs improving and also allowed me to question my motivations and assumptions relating to client care, behaviour and reasoning. Having used this model a few times now, I feel confident and empowered as I begin to realise gradual improvement to the skills I am reflection on.

P2: This in-depth reflecting gives me the that head space, rationale and direction needed to make decisions ... The stages require such detail that one begin to see things from multiple perspectives by the end of the exercise ... It allows me to appreciate what I have learntsometimes I don't realise that I know a particular skill or knowledge ... Helps me learn the best way forward for future tasks...

P5: We become responsible for setting study objectives and goals ... We begin to realise what it is that we need to achieve to become competent ... through the process of reflecting and evaluating...

P7: The reflection component of our work which is bedded within key milestones of the module helps question what I am doing, why I am approaching situations in a particular way and to evaluate my level of competency with that of the profession's.... It also encourages a sense of can-do and creative attitude when confronted with challenging situations...

\footnotetext{
${ }^{51}$ For a full discussion on this proposal see A.Thanaraj, Constructive Reflection: Getting the Best Out of Reflective Learning, INTERNATIONAL JOURNAL FOR INNOVATION, EDUCATION AND RESEARCH (2017), available at: http://www.ijier.net/index.php/ijier/article/view/500/540.
} 
Drawing on these findings, curriculum designers should be able to design learning experiences in ways that develop in students the desired graduate attributes. Constructive reflection recognises the need to facilitate the reconceptualization of knowledge and learning by questioning, evaluating and critique of knowledge to draw higher levels of cognitive and moral development, whilst it aims to explicitly raise awareness of the necessary competent knowable, skills and attributes for professional practice through its constructive and methodological process. It allows a learner to learn from their experience, evaluate the experience and find new ways of working by drawing upon multiple perspectives. A successful professional learning process can be facilitated by an understanding of the rationale behind actions and the decision-making process, leading to conceptual change.

\section{H. Team Working}

Teamwork is critical to increase productive and creative work and relationships amongst colleagues and business stakeholders. Learning in communities or groups helps to contribute to a learner's personal, social and self-development.

P1: Working with my team in a fairly fast passed legal/business environment has made me realise how working together can help us more effectively meet the goals set in the project management system. Collaborating and checking each other's work improves the standard of work...

P2: ... requires team buy-in to meet deadlines and expected standard of work ... there is an expectation that the team leader is left with the work which members don't want to do, unable to do or where they have not completed a task, I am still not clear how to assign responsibility and accountability for teamwork ... I can see the benefit of learning about team working and improving the way I handle group situations as there is a lot of this in the jobs market. I am a firm believer that learning from mistakes is still good, helps me realise what not to do...

P4: What comes to mind is employment law-treatment of team members such as through the Equality Act 2010 or Health \& Safety at Work Act 1974...

P7: Team working has helped me improve my communication skills, social skills ... awareness of different working practices ... and the ability to manage the diversity we bring to our teams...

P8: I have improved my problem solving skills because of the 
opportunity to share ideas and learn new ways of thinking, critical thinking too, I am able to embrace different perspectives and evaluate them and some leadership skills in getting everyone to contribute to tasks...

The findings suggest that team work has a good impact on students' academic, personal and social development. The framework within the VLC is designed to promote teamwork should be situated in a constructivist approach to learning and it encourages learners to build upon existing knowledge and practices. This scaffolding approach helps to facilitate the development of team working and wider skills. However as participant 2 had commented there is still work to be done in the construction of the VLC activities in order to address team development process leading to better goal setting, dealing with different perspectives and general management of tasks. Some of these challenges of intercultural working within the VLC has been examined and discussed. ${ }^{52}$ The findings also show the importance of effective communication, the manner in which information is communicated and received and the challenge of doing so online.

\section{Adapting to Uncertainty}

Some aspects of law may be open to interpretation and carry a sense of ambiguity, particularly in areas where there are unresolved issues, a high degree of complexity or simply a lack of clarity in existing principles. In other cases, uncertainty can be found in unanticipated developments or previously unconsidered opportunities or outcomes. Teaching a student how to deal with uncertainty is one of those learning objectives which is challenging to achieve. ${ }^{53}$

P3: Practical and professional modules such as the VLC has helped me become more aware of the unstructured nature of how cases progress ... Although the employment law transaction calendar is on the practice management software, not all eventualities can be accounted for. As a team, we had to negotiate our way to manage changes and challenges.... Although initially we complained about it to

\footnotetext{
${ }^{52}$ A. Thanaraj, Internationalizing Education: Evaluating the Growth of Intercultural Communication and Competency in Students through an International Negotiation Project Using an Online Law Office, 6(1) Journal of PedAGOGIC DEVELOPMEnT (2016), available at: https://journals.beds.ac.uk/ojs/index.php/jpd/article/view/257.

${ }^{53}$ R. Hyams, On Teaching Students to Act Like a Lawyer: What Sort of Lawyer?, INTERNATIONAL JOURNAL OF CLINICAL LEGAL EDUCATION (2008), available at: http://journals.northumbria.ac.uk/index.php/ijcle/article/view/65.
} 
our tutor, we quickly realised that the reality of any professional practice will contain elements of uncertainty and in fact learning to handle it in a supervised environment has been helpful.

P4: The VLC is unique in that it gives you the opportunity to experience all sorts of real-life problems where a task or practical skills goes wrong ... Although this is discouraging and upsetting at that time, we were advised that the experience is still useful if we constructively reflected and evaluated what we have learnt and gaps in our learning ... This sort of experience - the reality of the work place-helps us develop confidence and an identity as to whom we are and how we address challenges...

\section{DISCUSSION}

The choice of using a grounded theory methodology in this study has been valuable. It has allowed me to discover the students' view and perception of the value of working on the virtual law clinic after completing a full transaction on the platform, rather than use my own observation and views to make improvements to the initiative. The perspectives of the students are most valuable to help generate a more improved initiative to capture the skills and aptitudes that need to be embedded and made more prominent into the learning via the VLC.

The VLC has brought to life professional experiences which students can learn from in a supervised environment. The hands-on, active and collaborative way of working has helped students gain direct experience of a professional environment with professional activities, relevant both for the legal sector and other wide ranging careers and the opportunity to think about what they are doing in a way to heighten meaning and understanding and to apply their learning to real-world problem solving. The use of experiential learning also equips students with experience of independent self-assessment and regulation which is a tool they can utilise at any stage in their working life.

Students worked in small teams/clinics. Learning together and sharing knowledge, students also begin to learn new and improved ways of working. ${ }^{54}$ The findings resonate with Hernandez's ${ }^{55}$ recommendation that

\footnotetext{
${ }^{54}$ V. Tinto, Classrooms as Communities: Exploring the Educational Character of Student Persistence, 68(6) JOURNAL OF HigHER EDUCATION (1997), access available from: https://www.jstor.org/stable/2959965?seq=1\#page_scan_tab_contents.

${ }^{55}$ S. A. Hernandez, Team Learning in a Marketing Principles Course: Cooperative Structures that Facilitate Active Learning and Higher Level Thinking, 24(1) JOURNAL OF MARKETING EDUCATION (2002), available at http://journals.sagepub.com/doi/abs/10.1177/0273475302241009.
} 
the value of team working is amplified when the "creation of cooperative structures that are effective in promoting active and deep learning" ${ }^{56}$ There is also some awareness of the need to maintain responsibility, professionalism and accountability in both personal and group contexts online.

Importantly, the VLC is also used as a medium for students to receive a holistic form of learning about professionalism and to gain awareness of the reality of the emerging changes to the delivery of legal services. Through substantial training and experience in complex problem-solving exercises, project management, working in teams online, there is scope and opportunity to develop professional judgement skills, develop multiple forms of competent practice, skills, capability and qualities necessary for being a successful, creative and effective professional in a complex, uncertain, changing professional sector. The VLC platform gives students the confidence to take risks, develop their confidence to work with uncertainty and unpredictability, promote self-awareness through reflective learning. Consequently, this can empower their development of personal and professional identity.

As a training tool, it provides situations for learning where there are no right answer or right technique for practical skills (except for working within the constraints of ethical and conduct rules of the profession), provide real-world learning situations, provide activities that are meaningful to participants and provide learning situations that are both fun and challenging. It is through this process that students become self-directed and begin to develop their own ways of handling professional tasks with a repertoire of communication skills, understanding the value of integrity, respect, diligence and confidentiality. Importantly, they also begin to appreciate the role of technology, privacy and security in legal practice and become aware of the necessity of legal ethics, personal responsibility and accountability online.

The findings demonstratedthat some students gain a holistic learning experience both within the context of legal education and development as a professional ready for employment in an uncertain and fast moving economy, thus contributing towards their development and identity as "the proficient new lawyer".

However, awareness and knowledge around dealing with business change, organisational culture, business models, workload and general business literacy were not as prevalent as the extent to which a student's

\footnotetext{
${ }^{56} \mathrm{Ibid}$, at 76.
} 
should be able to demonstrate their commercial awareness. There is evidence that students are able to identify their skills, knowledge and abilities in an agile workplace, with a capacity to reflect on their strengths and weaknesses. As such, a number of skills and attributes which the author would deem as key employability factors which were not present form the data.

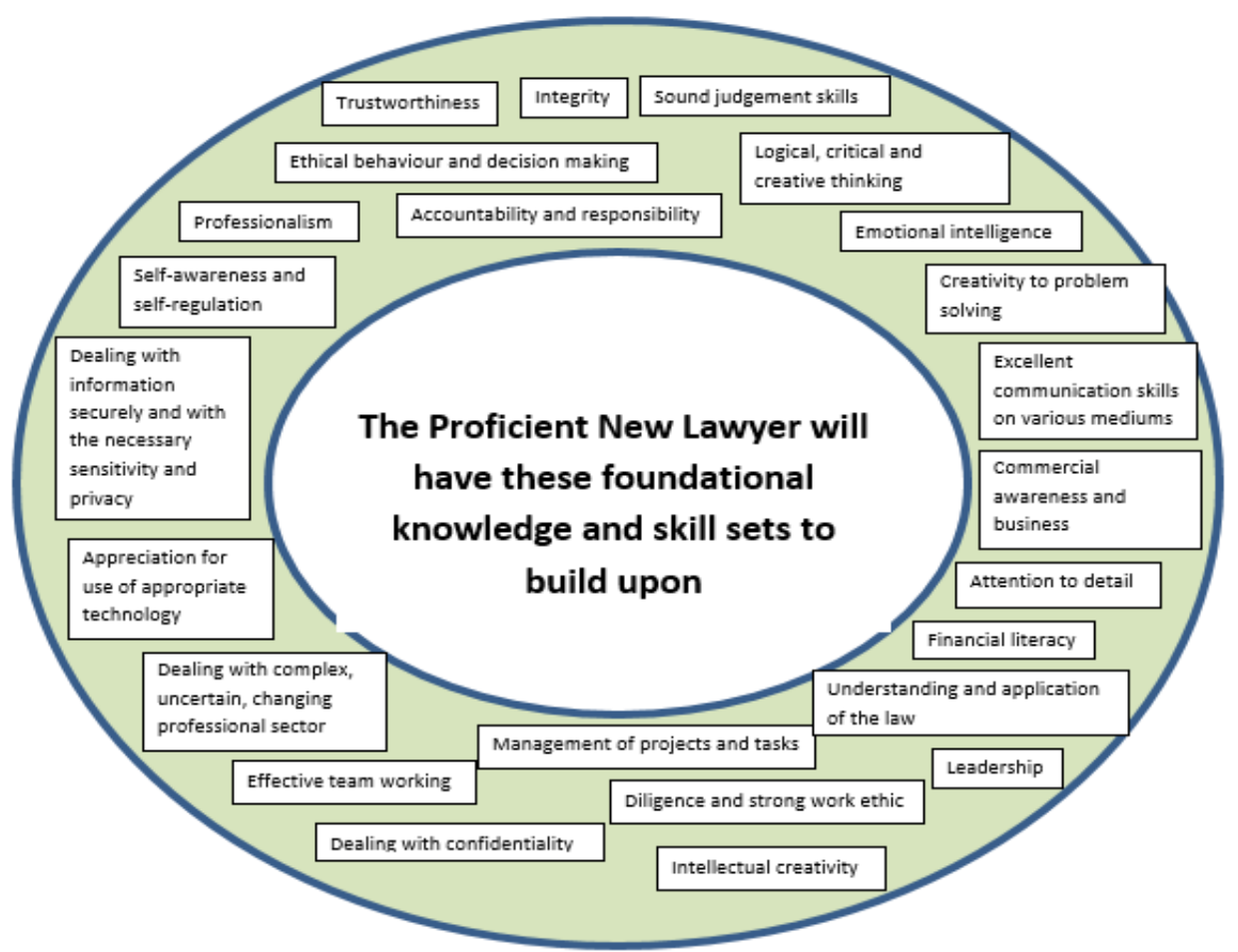

Fig. 1 The Skills and Attributes of "The Proficient New Lawyer".

\section{A REFLECTION ON THE IMPROVEMENTS NEEDED TO ENHANCE THE DESIGN FOR LEARNING IN THE VLC}

By understanding more fully the skills and aptitudes which students are able to articulate after their VLC experience, it is now possible to modify to improve the existing curriculum and develop innovations in the VLC to allow students to gain further opportunity to develop into "the digitally proficient lawyer". In addition, the SRA's day one outcomes ${ }^{57}$ and the

\footnotetext{
${ }^{57}$ A new framework for work based learning: Consultation - Annex 1-Day one outcome-

"Knowledge of ... the rules of professional conduct (including the accounts rules) ... understanding of ... the values and principles on which professional rules are constructed...", available at: http://www.sra.org.uk/solicitors/qlts/day-one-outcomes-table.page.
} 
newly published "Foundations for Practice" helpful benchmarks to begin reflecting on making improvements to the VLC initiative and curriculum and explore how we can offer opportunities and experiences to build students' character and aptitude, ethics and identity. In this reflection, I have considered:

- The types of learning activities to form the VLC training in order to develop the specific set of attributes along with the expected subject knowledge and skills.

- How best to approach the design of interactive activities within the application in order to facilitate the development of these attributes ${ }^{59}$.

- Mapping the development of these attributes to the aims, intended learning outcomes and assessment of the VLC training ${ }^{60}$.

- Integrating regular opportunities for students to be aware of and reflect upon their learning experiences and professional development as a result of the VLC training ${ }^{61}$.

Having reviewed the papers which I have written on the subject of the VLC and after further reflection on the development of the necessary skills and attributes of "the digitally proficient new lawyer", then I aim to:

Improve the curriculum design by the facilitation of understanding, supporting and guiding students to develop their autonomy, creativity and self-awareness through the constructive reflection process and an additional step to encourage a student-tutor conversation about the findings from the reflection and action-plan any refinement and change.

$>$ Improve the learning design of the curriculum embedded in the VLC such as implementing learning which integrates the testing of acquired knowledge through the use of feedback mechanisms within activities, encouraging students to provide detailed authentic assessments of their performance, facilitating the development of a professional ethos and identity underpinned by integrity, trustworthiness and strong work ethic,

\footnotetext{
${ }^{58}$ Foundations for Practice: The Whole Lawyer and the Character Quotient by the Institute for the Advancement of the American Legal System (IAALS), available at: http://iaals.du.edu/educatingtomorrows-lawyers/publications/foundations-practice-whole-lawyer-and-character-quotient.

${ }^{59}$ After a literature review on appropriate design pedagogy, a reflection on design improvements can be seen in A. Thanaraj, Evaluating the Potential of Virtual Simulations to Facilitate Professional Learning in Law: A Literature Review, 6(6) WORLD JOURNAL OF EDUCATION (2016), available at: http://www.sciedu.ca/journal/index.php/wje/article/view/10607.

${ }^{60}$ An initial proposal for a digital lawyering framework can be seen in A.Thanaraj, Making the Case for a Digital Lawyering Framework in Legal Education, INTERNATIONAL REVIEW OF LAW (2017).

${ }^{61}$ An initial proposal of a constructive reflective learning structure can be seen in A.Thanaraj, Constructive Reflection: Getting the Best Out of Reflective Learning, INTERNATIONAL JOURNAL FOR INNOVATION, EDUCATION AND RESEARCH (2017), available at: http://www.ijier.net/index.php/ijier/article/view/500/540.
} 
embedding creativity, independent thought and the freedom to express oneself whilst noting the need to tackle processes ethically, and to take carefully calculated risks where appropriate and learn and improve if errors are made.

$>$ To consider both the curriculum and learning design more fully so that the importance of skills and qualities which were not present from the findings of the current study can be addressed fully.

$>$ Encourage students to set learning goals and have the confidence to evaluate their own performance against benchmark standards. Taking this step towards becoming independent learners and taking responsibility for their learning and meeting learning goals, students will gain the skills to evidence their strengths and evaluate their learning and progress and articulate their transferable skills in a workplace.

To inform students of where the learning outcomes tie in with activities in the VLC and how these are related to defining learning targets and reflective practice. Students are to be encouraged to add their own aims to learning outcomes which is both motivating and enables them to reach their full potential, with a particular focus on the skills and qualities which were not present from the current study.

\section{CONCLUSION}

The study set out to gain an insight into the perception of students' employability skills, personal attributes and values using a grounded theory methodology. There are ten students volunteered and participated in the active interview process, after having completed three months of work on the training platform. The analysis of the interview shows that there are a number of key employability skills which students perceive they have developed or become aware of after their experience with the VLC curriculum.

These are: commercial awareness, professionalism and principles of values and justice, intellectual creativity, critical and creative thinking, developing originality of thought, creative problem solving, digital professional skills, project/case management, engagement with personal and professional development, collaboration, independence and work ethic and coping with uncertainty.

The paper argues that the underpinning requirement for all attribute development is to embed high quality learning, teaching and assessment methodologies based on the paradigm of constructivism, based around strong pedagogy of authenticity, experiential learning and relevant 
professional skills necessary for today's modern professional practice. The reflection above will be used as a guiding thought to continue with further improvements to the VLC and its curriculum.

Ideas and concepts are formed during learning experiences and embedded in the process of creating and rebuilding new and existing knowledge which will help to (a) raise awareness of these skills and abilities, (b) improve on the skills, knowledge and personal attributes already acquired, (c) demonstrate how their knowledge and skillset may be applied to different situations and articulate this to potential employers, and (d) continually improve oneself professionally.

The paper also highlights the benefits of learning via the VLC because of its wealth of skills and aptitudes and experiential lawyering which offers an opportunity for students to gain insight into the emerging trends in legal practice. 